\title{
Digital Deceit: Fake News, Artificial Intelligence, and Censorship in Educational Research
}

\author{
Joanna Black ${ }^{1}{ }^{\circledR}$, Cody Fullerton ${ }^{2}$ \\ ${ }^{1}$ Department of Curriculum, Teaching, and Learning, Faculty of Education, University of Manitoba Winnipeg, \\ Manitoba, Canada \\ ${ }^{2}$ Elizabeth Dafoe Library, University of Manitoba Winnipeg, Manitoba, Canada \\ Email: Joanna.Black@umanitoba.ca, Cody.Fullerton@umanitoba.ca
}

How to cite this paper: Black, J., \& Fullerton, C. (2020). Digital Deceit: Fake News, Artificial Intelligence, and Censorship in Educational Research. Open Journal of Social Sciences, 8, 71-88.

https://doi.org/10.4236/jss.2020.87007

Received: May 29, 2020

Accepted: July 10, 2020

Published: July 13, 2020

Copyright $\odot 2020$ by author(s) and Scientific Research Publishing Inc. This work is licensed under the Creative Commons Attribution International License (CC BY 4.0).

http://creativecommons.org/licenses/by/4.0/

\begin{abstract}
Never has it been more urgent for educators to be aware of the perils of research in education using digital searches in today's world of disinformation, misinformation, artificial intelligence and censorship. As a result, we are more reliant on strong researchers than ever before. In the discipline of Education, students are often asked to research issues pertaining to curricula, pedagogy, educational information and theories. Pupils are using Internet and digital library searches to gain knowledge within public and private K-12 schools and within higher education. In this article, an Educational Librarian and an Education Professor outline their approach to educating all Faculty of Education students about using digital platforms in relation to unmasking fake news, artificial intelligence (AI) usage, and increasing Internet censorship. Using case study research, we examined 34 Bachelor of Education students in training at the high school level who created environmental digital art projects. Information/media literacy was taught in order to provide students with the necessary tools to identify credible, diverse, well-informed, strong, and robust research. In addition, they needed to be able to discern when artificial intelligence was utilized. Outlined are students' projects. Our findings include "top ten" practical suggestions for educators at all levels when teaching students about effective researching in our current digital era.
\end{abstract}

\section{Keywords}

Educational Research, Student Research Methods, Educational

Media, Media Literacy, Critical Literacy,

Information Literacy 


\section{Introduction}

In the last three decades, especially in the last five years, misinformation/disinformation, artificial intelligence (AI), and suppression have been alarmingly increasing and intensifying and therefore we feel an impelling need to address this in our professional practice. Since the advent of the Internet in 1992 and the emergence of social media within the general populace approximately a decade later (Jones, 2015), many teachers are finding it more difficult to guide our students in effective research. Educators often ask their students to undertake research in education. By doing so, youths become better informed about education: specifically gaining knowledge and skills about teaching and learning, designing curricula and learning about historical and theoretical issues. We have found that many students within higher education are ill-equipped to conduct proper research without proper training. With this problematic situation in mind, we have tried to address this dilemma. Moreover, with the closing down of some libraries (Finch, 2019; Gwiazda, 2014; Voliva, 2016) students are relying more on digital information. At the same time libraries that remain open are often increasingly embracing digital technologies as library funding decreases resulting in budget cuts. Therefore, it makes common sense that librarians are moving towards purchasing digital texts and buying these selectively so that some current publications are currently sitting empty in our contemporary digital library shelves (Ahsan, 2018). With this occurring, it has never been more important to foster good research skills in our youths as many of our students are researching digital texts not only in schools, but also from home. There is a crucial need as many children are forced to be increasingly reliant on digital information for those to have the technology readily available. As an Education Professor and Educational Librarian within higher education, we have found that because of our changing society-pre, during, and we conceive, post COVID19we have to be increasingly careful to guide our students well in gathering digital information. In this complex binary world, we believe it is imperative to address what is occurring in our digital platforms relating to the proliferation of fake news, the expansion of artificial intelligence, and escalating censorship (Association for Media Literacy, 2020; Center for Media Literacy, 2020; Journell, 2019) for all levels of teaching and learning from kindergarten to grade twelve and within higher education.

\section{Obstacles in Library Searches in Education}

\subsection{Fake News}

Much has been made of so-called "fake news" in recent years: this term being brought into mainstream media by our current era ${ }^{1}$. There are three things you

\footnotetext{
${ }^{1}$ Fake news is proliferating as is clearly delineated by a certain reality star-turned politician. Graves, (2018) "How Trump Weaponized "Fake News" for his own Political Ends." Pacific Standard. https://psmag.com/social-justice/how-trump-weaponized-fake-news-for-his-own-political-ends
} 
should know about this type of news: firstly, misinformation which is the unintentional spread of false information; secondly, disinformation (the more maniacal of the two) which is false information deliberately presented as true; and thirdly through weaponization, a phrase referring to the undermining of legitimate news through implying it is uncredible, tenuous, and unjustifiable. Also associated to this is the practice of undercutting well researched news through the personal unfounded attacks on reporters and experts at large (Journell, 2019). There is, however, utility in understanding that there is a difference, as these can be equally dangerous to the unwitting listener ${ }^{2}$. Someone misleading you accidentally usually occurs because he/she did not check, or did not want to check, the source of information or are repeating something to sound knowledgeable. Nevertheless, he/she is representing speech as true, in the same fashion as disinformation.

Fake news is not a new phenomenon. In 1835, the New York Sun published a series of stories about how a prominent British astronomer observed giant manbats, blue skinned goat-like creatures, and a temple made of sapphires on the moon (Standage, 2017). This paper was one of the first to rely mostly on advertiser revenue than subscriptions As a result of disinformation, the New York Sun quickly became the bestselling newspaper in the world, for a short time, which greatly increased its advertising revenue (Standage, 2017). Of course the stories were not true, but the point was to sell papers: not print the truth. This newspaper was publishing disinformation to make money, while others sometimes print misinformation because of a bad source. Newspapers are a great example because many of them rely on their reputation in order to remain viable. If one bad story is printed in every one hundred or one thousand newspapers, then the text is considered a reliable source (Pant \& Trombetta, 2019). Even the New York Sun survived the scandal that followed the fake moon story because most of what it printed was, in fact, genuine (Standage, 2017) (Refer to Figure $1)$.

The proliferation of information has left formal edited news outlets with one aspect that is important and lacks in unedited, informally published social media sites such as YouTube channels, Instagram and Twitter and other online content: their credibility. But with subscriptions at an all-time low for traditional media sites, (Barthel, 2019), those credible news sources now make most of their money with online advertisements, which are calculated by a simple metric: clicks. Advertising will not make much money if few people look at them, and people controlling online platforms using AI are experts at keeping count (Lombard \& Snyder-Duch, 2001).

Disinformation is increasingly insidious today as its use is becoming more

\footnotetext{
${ }^{2}$ An recent disastrous example of a fake news outcome for instance was Donald Trump exclaiming enthusiastically the possible effectiveness of the malaria drug, hydroxychloroquine, touting it as a "game-changer" and wanting Americans sick with COVID19 to take the drug. It was later found that more people died who were given this drug than those who were not given the drug. It was also found that the drug has severe side effects (CBS News, 2020; Rowland, 2020).
} 


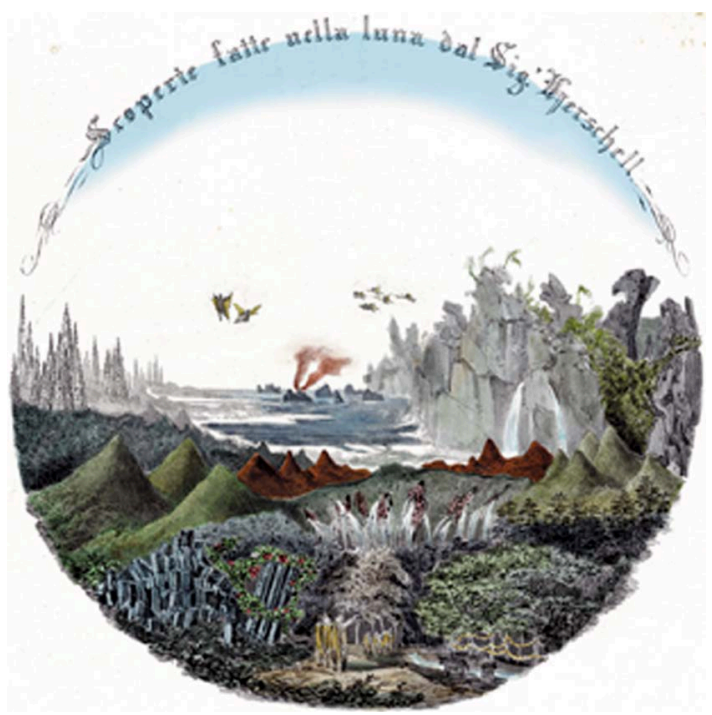

Figure 1. Fake news from historical 1835, The new york sun.

popular and uncritically accepted. Garrett (2019) terms another new type of fake news stemming from disinformation: he calls it a weaponized phrase (p. 18). It is used as an unethical and ungrounded dismissive defence to slander and smear credible news in the attempt to portray it as false. An example of this is the current American President Donald Trump's tactics in which he derisively attacks experts, journalists, and critics personally and professionally who disagree with his viewpoint and interests. Using smearing as a tactic, people utilizing this type of fake news similar to Trump attempt to undermine the credibility of legitimate in-depth journalism and the knowledge of experts. Over and over we see the effect of providing so called, "red herrings" to confuse, distract and undermine ideas. The intention is to cause doubt and disbelief with the public towards legitimate, fact-based expertise (Garrett, 2019).

So why is there a proliferation of fake news? There are many reasons including money, influence, persuasion, control, and acquisition of power (Alcott \& Gentzkow, 2017; Levy, 2017; Journell, 2019). Another reason fake news has become more prevalent is information is spread more rapidly now than ever before and is more readily available to everyone. Internet sites such as Facebook, Twitter, Reddit, etcetera allow anyone with an active account to publish not only their opinion, but also to share others' opinions. This allows everybody to be a journalist of sorts, self-publish whatever they like, free of professional ethics or an editor's expertise. Knowing that fake news is common can help educators understand it and recognize why we should not believe everything we read.

Developing strong research skills is important. Why? To discern reliable, well researched and well-founded information is crucial. Also, as humans it has been noted by psychologist and sociologists that we often have tendencies to seek out information that confirms our values and beliefs. This is called motivated reasoning - another term for this commonly used is confirmation bias (Journell, 2019). Consequently, students can easily conduct research that confirms their 
already held beliefs rather than gathering and learning about opposing differing perspectives and through this updating one's own views to embrace this new information (Journell, 2019: pp. 20-21). Consequently, gathering information from authors that have differing views enables students to have at hand challenging perspectives that they then can academically critique.

In education research students should learn about the three types of fake news on the Internet including misinformation, disinformation and weaponization and the strategies used to smear credible news. As well learners should learn how to discern fake news, and how to conduct research from reliable sources that is well thought out, well researched, and written by experts within the field.

\subsection{Artificial Intelligence}

Artificial intelligence (AI), or machine intelligence, is defined as any device that perceives its environment and takes actions that maximize its chance of successfully achieving its goal (Poole, Mackworth, \& Goebel, 1998). Basically, the term is used to describe digital machines, usually computers, that mimic cognitive functions that are associated with the human mind such as learning or problem solving (Russell \& Norvig, 2009). As machines become more sophisticated, the term AI no longer applies to certain types of "intelligence" that were once on the cutting edge, such as optical character recognition (OCR), which is a common tool used by publishers and libraries to make electronic books screen-readable for those with visual disabilities: this is known as the AI Effect. Douglas Hofstadter (1979: p. 601) wrote “AI is whatever hasn't been done yet," meaning, that previously we would have considered OCR to be on the cutting edge of AI, whereas now it is considered simply another common computational function, and not "intelligent. AI has a profound impact on modern society, ranging from taken for granted, now acceptable voice activated assistants, like Siri or Alexa, and recording one's Gmail with suggestions to move an email to a particular folder, to having AI commonly document and use one's computer searches to further advertise online items to the user. Currently, $\mathrm{AI}$ is limited in its applications, with the ultimate goal of being able to recreate a human's cognitive functions with machines. A problem that is far more difficult and complex than computer scientists originally supposed, is that humans not only perceive the space around them, they constantly make judgments and apply common sense to situations; however, AI cannot do this, yet. This is one of the most significant struggles in AI: it is known as the Frame Problem (McCarthy \& Hayes, 1969).

One of the most common appearances of AI in the media is deep fakes. These are a type of media, usually a photo or video, in which a person is replaced with another person's likeness. This technology is predominantly used in video, which makes it appropriate for films. The 2016 film, Star Wars. Rogue One, (Figure 2) utilized this technology to impose the likeness of Carrie Fisher, Princess Leia, onto another actresses face, making it look like young Carrie Fisher (Muncy, 2018). 


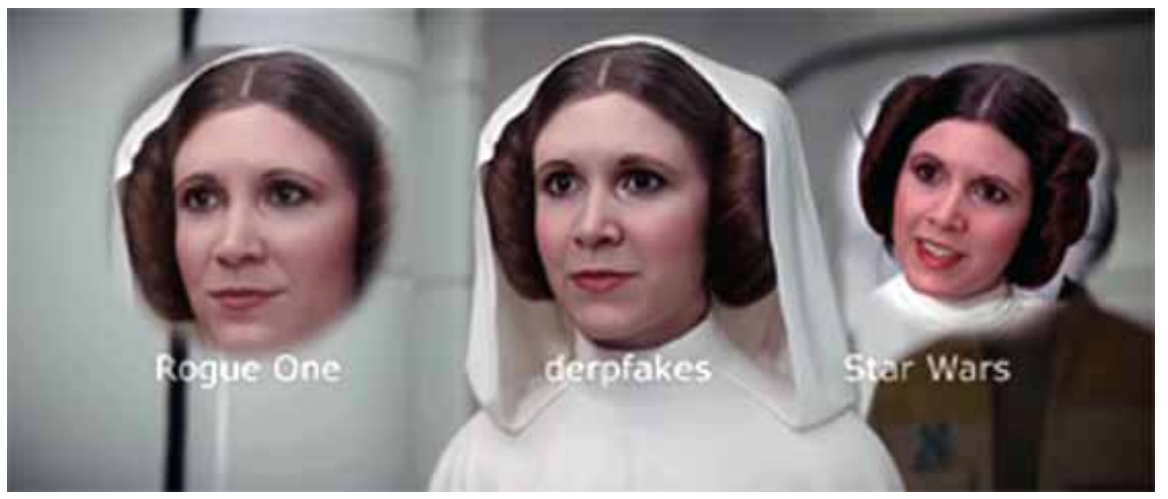

Figure 2. Deep fake example. Carrie fisher in the film, Star wars: Rogue one.

As most people are aware, however, this technology can and is being used in more nefarious ways. Deep fakes have been used to misrepresent politicians in videos, such as Argentina's president Mauricio Macri as Adolf Hitler and Germany's President Angela Merkel as Donald Trump (Scammell, 2018). These videos were meant to embarrass and discredit the politicians. This problem has even come to the attention of the White House, as the House Intelligence Committee held hearings in 2019 discussing the roll that deep fakes could play in swaying elections (Permanent Select Committee on Intelligence, 2019). However, there has been an effort to fight "fire with fire", most notably Jordan Peele's public service announcement video produced by Buzzfeed. In the video, Peele is speaking with the likeness of Barack Obama overlaid on top of his face (BuzzFeedVideo, 2018). The purpose of this video is to illustrate that deep fakes are easily produced and can fool those who do not fact check.

Part of artificial intelligence's role is used in what we believe are pernicious ways. Today individuals and organizations are now using software that targets digital users to manipulate opinions and influence their actions (Jalonick \& Balsamo, 2020; Neudert, 2017). This term computational propaganda is defined as methodical attempts to obscure, divide and even incense digital audiences through usage of automated bots, (algorithmically driven computer programs that are task driven), dummy accounts, and trolls (Woolley \& Howard, 2016). As Neudert (2017) writes, "Automated scripts equipped with big data work over social media to advance ideological viewpoints. Politicized social bots are one version of potentially malicious programs...computational propaganda [are used] to manipulate conversations, demobilize opposition, and generate false supports..." on social media sites (p. 3). Computational propaganda has digital technologies programmed to promote certain specific political and ideological perspectives to influence the masses. In education students should be knowledgeable about computational propaganda and its use in design and text in such text based and visual works as films, videos posters, graphic designs, and graphic website development.

In researching social media sites, students can develop skills in discerning the sites that Artificial Intelligence is used. They can be taught about the use of deep 
fakes, of altered photographs and videos to misinform the public. Further to this, young learners should be taught to recognize when computational propaganda is used and should be able to perceive automated bots, dummy accounts, and troll usage. This is particularly relevant on social media sites such as Twitter. One method is to check the authors of the text's credentials. Look at their profile: do they have a profile picture? What does their bio say? Do they predominantly retweet others' posts? How many followers do they have and who are they? What is their post's history? Answering these questions can at the very least help formulate an idea of who these authors are and what are their points of view. It is sometimes possible to detect if they are sincere or simply a troll or bot. It is important to remember that these methods are not always effective.

\subsection{Censorship}

After the highly politicized era of the 1960s in which the populace voice had great influence (Chomsky 2017), in 1971 a campaign first started by Lewis Powell who was a corporate attorney at that time. He argued that corporations had to run fiscal campaigns to control, marginalize and repress dissident anti-corporate ideas in higher education, churches, media, and academic texts (Hedges, 2017). As a result, in the last half century censorship has indeed been incredibly successful. Like most corporations, the elites have silenced those dissidents hostile to corporate concerns (Hedges, 2017: p. 1). Thus, in obtaining educational information through computer searches specific knowledge about search engines are important. Why is this the case?

The most popular search engine today is Google which dominates all others: it has $80 \%-90 \%$ of the market worldwide depending on geographic location (Naughton, 2018). As is stated by Naughton Google can “...shape the way you think...it's not a passive tool that you own and control, but the property of a huge corporation that has acquired strange-and in some ways unprecedentedpowers" $(2018$, p. 1). He harkens to the famous media theorist, Marshall McLuhan who states that human beings create tools and these same tools in turn shape us (Sobelman, Donaldson, McMahon, \& McLaughlin, 2002). We are indeed being shaped even if we are not cognizant of it by our computer. This is key: students need to be informed about what is occurring on the Internet regarding censorship.

Like most corporations Google runs on making money obtained through advertising revenue. It uses AI to collect data through Google Analytics where cost per click ratio is documented which allows these agencies to track minute-byminute each click of each user and thereby target customers documenting their personal and professional information (Auletta, 2010). In addition to this, Google censors information and sanitizes searches that are offensive to political regimes. Examples of this are stripping all information about Tiananmen Square in China's Google.cn engine, and complying with German laws to "screen" Nazi materials, or working with the Thailand government censoring any YouTube videos 
that defamed their current king (Auletta, 2010, pp. 134-135). We are not free of this sanitization in North America. By 2017, in the United States Google curbed the populace's easy access of leftist political sites by 55\% (Damon, 2017). Chris Hedges, the American award winning Pulitzer prize journalist writes, that the corporate elite who rule and, "who grasp that the reigning ideology of global corporate capitalism and imperial expansion no longer has moral or intellectual credibility, have mounted a campaign to shut down the platforms given to their critics [which] include blacklisting [and] censorship ..." Hedges (2017: p. 1) argues that if we had a free and properly functioning media system liberated from corporate control those sites that are currently censored would be easily accessible to all. They are not right now.

Another concern is that by using Google all individuals have different results as the Internet searches are shaped by Artificial Intelligence information gathered about the user. On a day-by-day, click by click basis AI gathers information about user preferences and uses this for advertising as well as for future Google searches. Therefore, and this is crucial: one person's Google search differs from another based on the same subject search. So for example, if one art teacher is searching on Google about the Chinese artist, Ai Weiwei, the search information would be far different from another person's search based on prior data collected about each researcher. This condition is called the Google Bubble, coined by Eli Pariser (2014) wherein there are significant differences in Google search results unique to the Internet searcher (Auletta, 2010; Wikipedia, 2020). This knowledge isolation is a result of narrowed viewpoints aligned to the searchers' own preferences. Therefore the creation of a myopic perspective may result because differing ideas from those of the searcher on the Internet can be blocked or be far more difficult to access. This is far different than the old days, pre Internet-pre 1992-of libraries and all sources being accessible in the same way to all individuals seeking to search out information with the use of cards, library text stacks, and interdisciplinary traditional loans of hardbound texts.

Ways to circumvent censorship are several. To teach students about differing viewpoints show them research from differing Internet sites that have dissimilar perspectives. Find sound informative sites that are censored such as Democracy Now, to learn to gather differing hard to obtain perspectives, and be informed using logic about differing viewpoints gained from these sites. Also students should be introduced to other search engines like DuckDuckGo, which is one that protects users' privacy, does not have advertisers "microtarget" users, avoids personalized search results, and thus does not utilize a filter bubble (Templeton, 2019). It consistently has the same data, organized in the same way on the site for all users who search results on a research subject like Ai Weiwei.

\section{Example: A Class Research Project}

\subsection{Background of the Case Study}

McClure \& Clink (2009) establish the following in their 2009 article, “...students 
struggle with understanding and valuing source material, and their teachers struggle with instructing them on source analysis" (p. 117). What seems apparent, and in some ways self-evident, is the sources students are citing are ones they can find in the time they have, given the constraints within Bachelor of Education courses; in this particular case it was a three-month course. Access to sources is one of the most influential factors when it comes to student citations (Biddix, Chung, \& Park, 2011; Tolar-Burton \& Chadwick, 2000). Pupils are aware that these need to be credible, but either lack the know-how to find them or would rather rely on search engines algorithms, where they can use plain language searches as opposed to spending the time locating texts using the library catalogue or databases (Emde et al., 2008; Martin, 2008). It appears that learners' "go-to" instrument for finding sources is publicly available search engines, so while training students to use library resources, we also chose to teach them how to evaluate those that they discover. By meeting them where they are positioned, we hope this will facilitate their understanding of what is credible and what is fake news. We undertook case study research in the Faculty of Education program at the University of Manitoba (Stake, 1995; Yin, 2017).

For this single case study research (Yin, 2017) the specific class taught was comprised of thirty-four Bachelor of Education (B.Ed.) students who were being trained to teach at the secondary level. As is typical of this type of research this class is a sample study representative of numerous higher education classes taught about library searches (Stake, 1995: p. 4). We gathered data through field notes, participant observation, collecting students' reflections, and final artworks, which included text-based, traditional art, and multimodal digital art. For the analysis we underwent categorical aggregation, direct interpretation, and looked at common patterns emerging as defined by Stake (1995: pp. 71-85). This course is called, "Arts Infusion in the Digital Age" and was taught during January to March 2020. Class participants enrolled had diverse backgrounds in the humanities and sciences including visual art to physical education, and science to mathematics.

During this class we addressed contending with digital deceit as an educator and as a librarian in a Canadian prairie university. B.Ed. students were asked to explore the theme of art in the Anthropocene examining current environmental destruction and to develop ideas and designs that would lead to the creation of a digital artwork (Figure 3). It was an arts integrated project correlating art and politics to science in teaching and learning. They were taught about the library website and what was available to them, about Boolean searches (that combine key words for the most effective results); the importance of using key terms, and about fake news, AI, and censorship.

\subsection{Artwork Process}

After the students experienced the library session they were given approximately one month to gather research information. Class participants worked in groups 


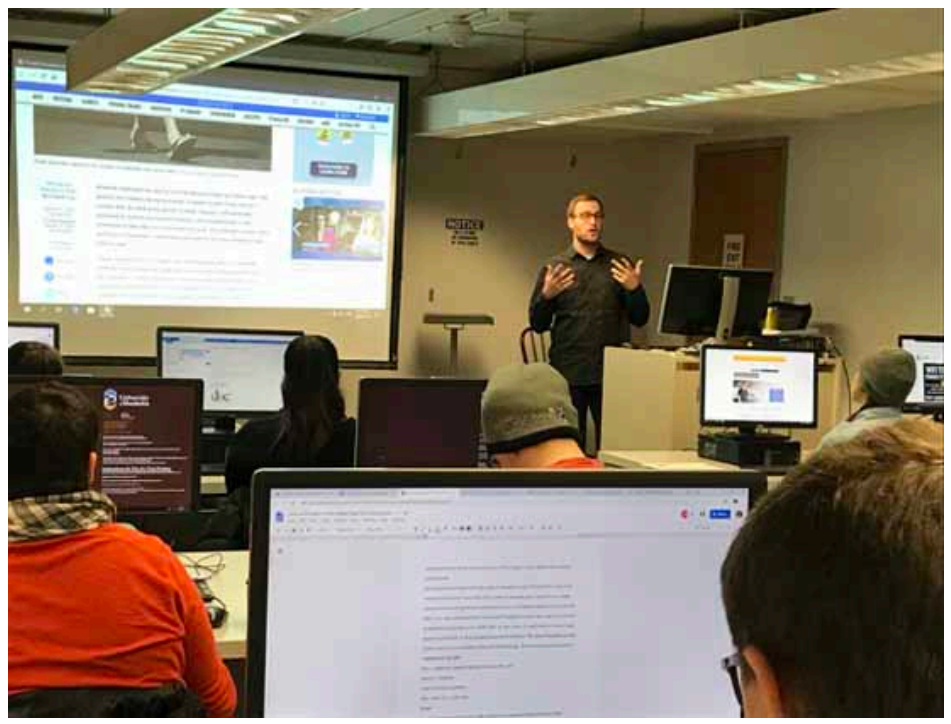

Figure 3. Photograph taken during a library session January $25^{\text {th }} 2020$. Photograph taken by Joanna Black.

of three or four people and selected such diverse themes to explore as survival in the Anthropocene in the next fifty years, polluted oceans, plastics and its impact, climate refugees, and decimated bee colonies on global levels. The project was comprised of undergoing a preproduction phase researching; a production phase making the digital art; and a postproduction phase in which students posted digital artworks on the Internet and also showed their work during class. One group comprised of students, Mark, Paula, Haley and Jaimel created a website and called their work, "Human Discord" addressing fake news: this is the group we will discuss further. (Refer to Figure 4, Figure 5 and Figure 6).

The group's website was designed to elucidate the differing thematic approaches to climate change as a whole including ice melting and carbon pollution. One component of the website was comprised of vignettes that had effective conversations between climate change deniers and those who believe it is actually occurring. The dialogue is posted as possible discussions. Rather than be dismissive these students utilized logic in their dialogic text. Outlined are differing points of view with the underlying attempt through the artwork to change a viewer's mind who denies climate change. In the website students articulated what they learned which were the different arguments regarding climate change to better prepare themselves for their futures as teachers.

Students' digital imagery is diverse collaged artworks. In order to make this they learned about new software to communicate their perspectives which included Adobe Spark. Fotor, Pixaloop, InVision, and Azure. Finally they learned about making digital art for this project. Many had not taken art since their early or middle years' schooling. In their discussion they voiced their experience that art and politics and education can be intertwined. They also reflected that they had met their own challenge of encouraging a productive discourse through compassion. Visual art, they stated, is not only about what is shared, but the way 


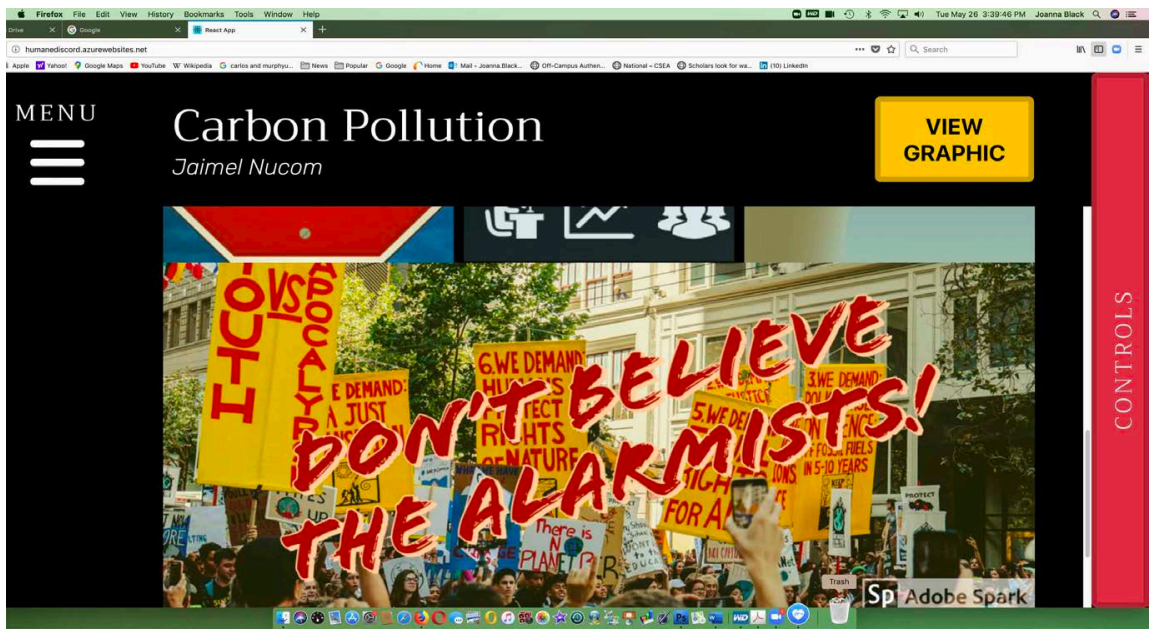

Figure 4. Screenshot of website, Human Discord by Jaimel Nucom. Image found at the website: http://humanediscord.azurewebsites.net/.

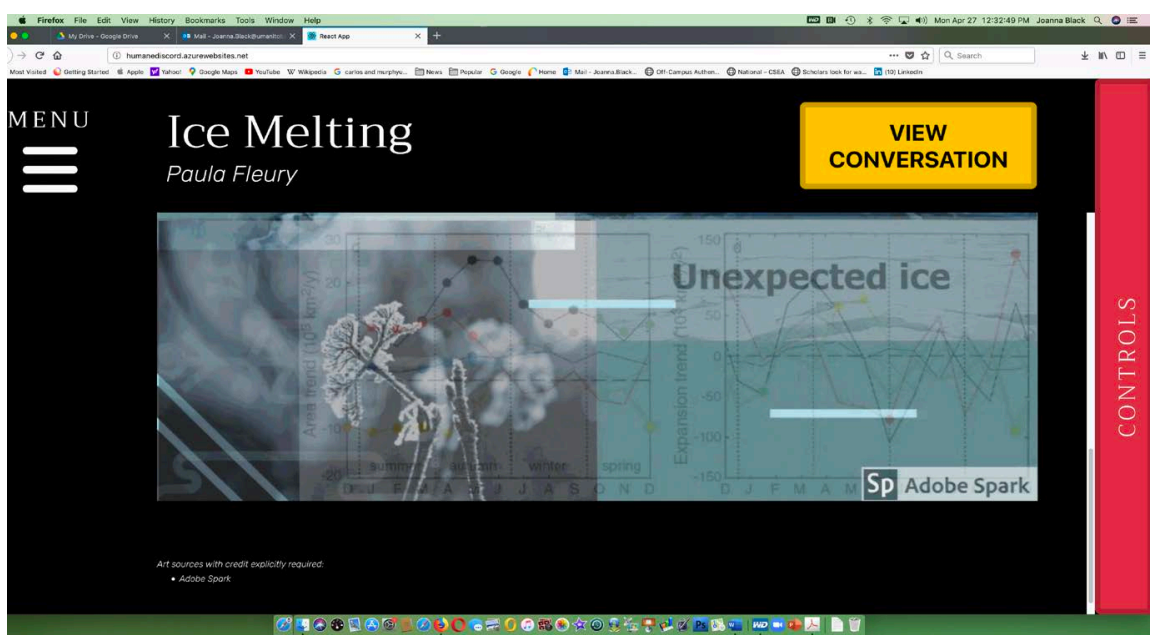

Figure 5. Screenshot of website, Human Discord by Paula Fleury. Image found at the website http://humanediscord.azurewebsites.net/.

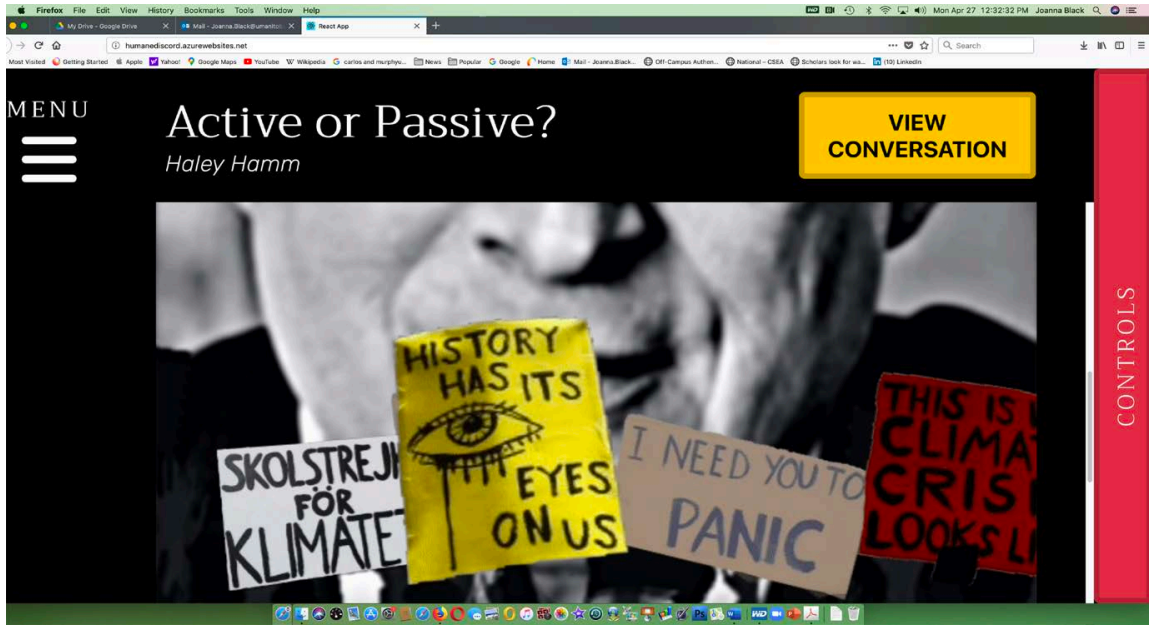

Figure 6. Screenshot of website, Human Discord by Haley Hamm. Image found at the website http://humanediscord.azurewebsites.net. 
it is shared thus referring to McLuhan (Sobelman, Donaldson, McMahon, \& McLaughlin, 2002). In the overall assessment of the experience the students stated that they found this project of benefit because they not only found ways in which to incorporate artistic design principles into their curriculum to engage the viewer, and to learn about digital visual artmaking employing art as activism, learning by making, and engaging in art for social change, but they also became involved with oppositional points of view diametrically opposed to their own within the artmaking process. For this project students had to collect research from diverse perspectives: they honed their library skills, discerned issues of fake news, sought for views that were far harder to find, and tried to create a more balanced website as a result.

\section{What Can Educators Do?-Addressing these Issues from the Perspective of a Librarian and Educator}

As a professional librarian and educator, we are constantly engaging in conversations with students and teachers about citations and source material. For our results of this study we have compiled a Top 10 list of what educators can teach their students about source credibility and authority.

\section{The Top 10 Action Tips}

\section{Teach students to:}

1) Consult Librarian for Reference Assistance: Librarians are trained searchers. When most people hear the term librarian, they think of public librarians: shelving books, assisting patrons with basic computer software, and planning community events. An academic librarian's job is often remarkably different from our public counterparts. Teaching, research, and professional development are often part of our duties. We are much more focused on instructing students and faculty members how to perform searches and find the information they require. So, when your students are beginning a research project, have them reach out to your librarian.

2) Examine the Context: Whenever being presented with new or conflicting information always look at the context. Teach about fake news, censorship and artificial intelligence. Instruct learners to take a look at similar sources or reviews. If students are dealing with an article, find who has cited it and look into this citation. If it is an image, teach students to run it through a reverse-image search. These tools such as tineye.com, labnol.org/reverse, duplichecker.com and many apps such as Reversee and Reverse Image Search are useful. This software uses image recognition to match your picture with other indexed images across the Internet: a classic example which is a great instance of artificial intelligence at work. This method is beneficial for finding the source of an image if you are unsure of its origin by discerning its colour and design to track its genesis.

3) Look at the Experts and Sites of Publication: Teach learners to not only determine whether a text and/or Internet site is reliable, but also whether the people 
writing this text are experts in the field they are researching. It is important for pupils to understand where they obtain their information. Unedited blogs are far different than papers written by experts in the field that are peer-reviewed. At any age it is important to differentiate between a text obtained from People Magazine and a peer-reviewed academic journal published by a university. Teach students to look at URL's and see if they are from universities, from established respected news sights, published books, and from peer reviewed books. Also, in our digital age it is important for readers to understand writers' raison d'être for creating texts. It is far different to write in order to contribute further academic knowledge in the field versus for example, making money, or for political persuasion. Students should learn to research the background of these sites and ask critical questions such as: Who published this site? Is it a reliable one? Was the text peer reviewed? Was this text written by someone knowledgeable in the field I am studying? What is the purpose of this site and this text? Is the writer considered an expert in his/her field?

4) Distinguish between Opinion and Evidence: It is imperative that educators should pay attention to the importance of developing their students' critical thinking skills (Wang \& Torrisi-Steele, 2015). Authors are trying to make a point or argue a side. You know what they say about opinions, everyone has one, but it is only credible if supported by evidence. Simply knowing the distinction can make learners more aware of the difference.

5) Check Yourself Before You Wreck Yourself: We all have biases. Ask your students to find information that disproves a theory. Is either theory supported by evidence? As an exercise, think of possible counter arguments.

\section{As educators you can:}

6) Collaborate with the Librarian in your School and Set Up In-Class Sessions about Information and Library Based Searches: Trust us, librarians love to show off their skills. Not only is inviting a librarian into the classroom useful for students, but often the instructors that attend sessions learn something as well. Krieb (2018) has shown that students who attend library instruction classes or visit the reference desk individually have statistically higher retention rates, and in some cases, attain higher grades. Librarians are not only willing to teach students about searching and using library resources, but also if you want a specific subject taught, for example fake news, do not hesitate to reach out to your local information professional.

7) Give Students Time to Research: Allow students the time to research well, understand their topic and therefore provide them with an in-depth learning experience. Instead of three weeks at the end of the semester, introduce the term paper near the beginning of class and build up to the final paper with smaller assignments as you progress through the course.

8) Teach about Cognitive Biases: Humans have a tendency to believe or look for information that confirms our beliefs and make us or the people we care about feel good. Also, conversely, we have a tendency to discount information 
that questions our beliefs and makes us or those we care about feel bad. This means we can believe information without evidence and discount information despite evidence. The antidote for this is during your research to always be aware of your initial feeling towards a piece of information, especially if you feel strongly about it one way or another.

9) Utilize Socratic Techniques: The Socratic Method focuses on using questions to examine values, principles, and beliefs. As the teacher, you can lead the class into discussions about topics and ideas that are meant to elicit "productive discomfort." Possible probing questions include: How would you summarize this? Could you elaborate? What's the reasoning behind your answer? These questions allow students to articulate their thought process. For more information on how to apply this teaching method, refer to Reis (2003).

10) Pertinent Dialogic Conversations: We recognize that many educators do this; however, we want to emphasize the importance of allowing traditional group and class dialogue when students research. This cannot be underestimated during and at the end of any research endeavor. Following extensive gathering of texts, allow students adequate time to read, comprehend, analyze, and interpret. Educators can ask students to talk, listen, and respond to findings and conclusions. This can be undertaken face-to-face or using software such as Zoom in our COVID-19 age. The importance of conversations during this process and most importantly at the end of it cannot be taken too lightly in order to foster students' comprehension of gaps in their knowledge and also to develop learners' balanced and well thought out understandings of the subject being studied.

\section{Conclusion}

We are continually battling fake news. As we write this article, we have entered the era of COVID-19 and it has indeed been a fast dive into pandemic life. Recently it was written in the local newspaper, "The top purveyors of fake news are coming together to battle an epidemic of misinformation... [social media] are using a combination of algorithms, new rules and factual warnings to try to knock down harmful coronavirus conspiracy theories... that regularly crop up on their services" (Winnipeg Free Press, 2020). Right now, in a matter that can be life/ death issues we have what The Guardian (2020a, 2020b) called an effective storm of fake news, cyber-crime, misinformation and disinformation. Indeed gathering texts through the Internet has always had its problems since it was formed almost thirty years ago ${ }^{3}$.

Researching and handling fake news and deep fakes well, contending with censorship, and dealing with artificial intelligence is fundamental to sound research training in education. As teachers we have a responsibility to teach students what is occurring in the digital world in regard to research searches to

\footnotetext{
${ }^{3}$ For example, one grade eleven student at a private school near Toronto, Canada was researching about WW2 and somehow became involved in a neo-Nazi site in which it took concerted effort and a considerable amount of time by police officers, a principal, teacher, and his parents to extricate the young researcher from the people who created that specific website (Black, 2002).
} 
combat the storm. Now more than ever we believe that it is critical to teach media literacy skills in relation to library searches. At all levels beginning in the early years and extending to higher education, we argue that educators should meet the challenge of this storm. We encourage teachers to continue to cultivate students' critical research expertise so that learners can better discern fact from misrepresentation and informed texts from deceit and bias. Combating motivated reasoning/confirmation bias is critical for students who graduate and enter our new complex world of COVID-19 and post COVID-19. They need to be trained so that they can adapt, locate, discover, and handle masses of reliable and unreliable information, and therefore act as critical global citizens. Through development of such skills as problem solving, and media literacy, youths will become young adults who can employ deep critical understandings in all aspects of their lives (Wang \& Torrisi-Steele, 2015). This will affect how young learners learn, understand and contribute to their own comprehension of the world in which they live now and in their future as adults.

The digital world is embedded in our way of life. It has incredible benefits, is a rich resource of not only finding information but of creating and communicating ideas that are expressed in multimodal ways. We cannot see going back to a world without the Internet. In our complex digital lives, it is not surprising that there is a new appreciation for and keen interest in Marshall McLuhan's ideas as of late: of the importance as we create and shape technology, of people also recognizing the role media has in shaping us (Sobelman, Donaldson, McMahon, \& McLaughlin, 2002). We need our students to realize the significance of digital media and how it is reconfiguring ways we acquire knowledge, learn about, discern and work with it so that they can combat the negative effectives of our digital world. By being aware metacognitively we can therefore prevent getting sucked into what McLuhan called the technological vortex. We can have some control over not only what information we gather, but also how we access it, how we read it and discern what is valid and reliable (Sobelman, Donaldson, McMahon, \& McLaughlin, 2002). We can teach students the skills needed in discerning fake news, the ways to combat censorship and artificial intelligence so that they can detect the way in which we are affected in our technologically mediated lives as we are submerged in the exciting, tumultuous, and engaging turbulences of our digital world.

\section{Conflicts of Interest}

The authors declare no conflicts of interest regarding the publication of this paper.

\section{References}

Ahsan, S. (2018). Simply Put, Libraries Are Incredible. National Post. https://nationalpost.com/entertainment/books/simply-put-libraries-are-incredible

Alcott, H., \& Gentzkow, M. (2017). Social Media and Fake News in the 2016 Election. 
Journal of Economic Perspectives, 31, 211-236. https://doi.org/10.1257/jep.31.2.211

Association for Media Literacy (2020). Teaching Media Literacy. https://aml.ca

Auletta, K. (2010). Googled: The End of the World as We Know It. Virgin Books.

Barthel, M. (2019). Newspaper Facts Sheet. PEW Research Center. https://www.journalism.org/fact-sheet/newspapers/

Biddix, J. P., Chung, C. J., \& Park, H. W. (2011). Convenience or Credibility? A Study of College Student Online Research Behaviors. Internet and Higher Education, 14, 175-182. https://doi.org/10.1016/j.iheduc.2011.01.003

Black, J. (2002). Topsy-Turvy Teacher-Student Relationships: An Examination of Digital Multimedia Teaching and Learning. Doctoral Dissertation, Toronto: University of Toronto.

BuzzFeedVideo (2018). You Won't Believe What Obama Says in This Video! https://www.youtube.com/watch?v=cQ54GDm1eL0\&feature=emb_logo

CBS News (2020). More Deaths No Benefit from Drug Touted by Trump to Treat Coronavirus Study Finds. New York: CBS News.

https://www.cbsnews.com/news/coronavirus-hydroxychloroquine-study-more-deathsno-benefit-drug-touted-trump

Center for Media Literacy (2020). Media Literacy in the USA. https://www.medialit.org/reading-room/media-literacy-usa

Chomsky, N. (2017). Manufacturing Consent: Noam Chomsky and the Media [YouTube]. https://www.youtube.com/watch?v=EuwmWnphqII

Damon, A. (2017). Google Intensifies Censorship of Left-Wing Websites. World Socialist Website. https://www.wsws.org/en/articles/2017/09/19/goog-s19.html\#

Emde, J., Currie, L., Devlin, F., \& Graves, K. (2008). Is Good Enough OK? Undergraduate Search Behavior in Google and in a Library Database. In C. Ury, F. Baudino, \& S. Park (Eds.), Brick and Click Libraries: Proceedings of an Academic Library Symposium (pp. 58-63).

Finch, D. (2019). Closing Libraries Means Abandoning Society's Most Isolated and Vulnerable. The Guardian.

https://www.theguardian.com/commentisfree/2019/aug/02/closing-libraries-vulnerable -mental-health

Garrett, H. J. (2019). Why Does Fake News Work? In W. Journall (Ed.), Unpacking Fake News: An Educator's Guide to Navigating the Media with Students (pp. 15-29). New York: Teacher's College Press.

Graves, L. (2018). This Is Sinclair, the Most Dangerous US Company You've Never Heard of. The Guardian.

https://www.theguardian.com/media/2017/aug/17/sinclair-news-media-fox-trump-whi te-house-circa-breitbart-news

Gwiazda, W. (2014). Canadian Library Association Concerned with Wave of Library Closures.

https://www.rcinet.ca/en/2014/01/14/canadian-library-association-concerned-by-waveof-government-library-closures

Hedges, C. (2017). The Silencing of Dissent. Truthdig. https://www.truthdig.com/articles/the-silencing-of-dissent

Hofstadter, D. (1979). Gödel, Esher, Bach: An Eternal Golden Braid. Basic Books.

Jalonick, M. C., \& Balsamo, M. (2020). Intelligence Officials Say Russia Boosting Trump Candidacy. New York: The Associated Press. 
https://apnews.com/4912baca0c4cbc6cb7a3580f4f3c9b96

Jones, M. (2015). The Complete History of Social Media: The Founding of Online Networking. https://historycooperative.org/the-history-of-social-media

Journell, W. (2019). Unpacking Fake News. New York: Teachers College Press.

Krieb, D. (2018). Assessing the Impact of Reference Assistance and Library Instruction on Retention and Grades Using Student Tracking Technology. Evidence Based Library and Information Practice, 13, 2-12. https://doi.org/10.18438/eblip29402

Levy, N. (2017). The Bad News about Fake News. Social Epistemology Review and Reply Collective, 6, 20-36. http://wp.me/p1Bfg0-3GV

Lombard, M., \& Snyder-Duch, J. (2001). Interactive Advertising and Presence: A Framework. Journal of Interactive Advertising, 1, 56-65. https://doi.org/10.1080/15252019.2001.10722051

Martin, J. (2008). The Information Seeking Behaviour of Undergraduate Education Majors: Does Library Instruction Play a Role? Evidence Based Library and Information Practice, 3, 4-17. https://doi.org/10.18438/B8HK7X

McCarthy, J., \& Hayes, P. J. (1969). Some Philosophical Problems from the Standpoint of Artificial Intelligence. In B. Meltzer, \& D. Michie (Eds.), Machine Intelligence 4 (pp. 463-504). Edinburgh: Edinburgh University Press.

McClure, R., \& Clink, K. (2009). How Do You Know That? An Investigation of Student Research Practices in the Digital Age. Portal: Libraries and the Academy, 9, 115-132. https://doi.org/10.1353/pla.0.0033

Muncy, J. (2018). This Video Uses the Power of Deepfakes to Re-Capture This Character's Appearance in Rogue One. Gizmodo.

https://io9.gizmodo.com/this-video-uses-the-power-of-deepfakes-to-re-capture-th-182 8907452

Naughton, J. (2018). What's the Biggest Influence on the Way We Think? The Guardian. https://www.theguardian.com/commentisfree/2018/sep/09/google-biggest-influence-o n-way-we-think

Neudert, L. S. (2017). Computational Propaganda in Germany: A Cautionary Tale. Oxford: Oxford University.

https://scholar.google.ca/scholar?hl=en\&as_sdt=0\%2C5\&q=lying+press+or+L\%C3\%B Cgenpresse+history+of\&btnG

Pant, A., \& Trombetta, F. (2019). The Newsroom Dilemma. https://doi.org/10.2139/ssrn.3447908

Pariser, E. (2014). Beware of On-Line Filter Bubbles. Ted Talks. https://www.ted.com/talks/eli_pariser_beware_online_filter_bubbles?language=en

Permanent Select Committee on Intelligence (2019). Hearing: National Security Challenges of Artificial Intelligence, Manipulated Media, and "Deepfakes".

Poole, D., Macworth, A., \& Goebel, R. (1998). Computational Intelligence: A Logical Approach. New York: Oxford University Press.

Reis, R. (2003). The Socratic Method: What Is It and How to Use It in the Classroom. Speaking of Teaching: Stanford University Newsletter on Teaching, 9.

Rowland, C. (2020). Anti-Malarial Drug Trump Touted Is Linked to Higher Rates of Death in VA Coronavirus Patients, Study Says. The Washington Post.

https://www.washingtonpost.com/business/2020/04/21/anti-malarial-drug-trump-tout ed-is-linked-higher-rates-death-va-coronavirus-patients-study-says/

Russell, S. J., \& Norvig, P. (2009). Artificial Intelligence: A Modern Approach (3rd ed.). 
Upper Saddle River, NJ: Prentice Hall.

Scammell, R. (2018). Deepfakes: AI Video Tool Could Make Fake News Easier to Create and Harder to Spot. Verdict. https://www.verdict.co.uk/deepfakes-ai-video-tool-fake-news

Sobelman, D., Donaldson, C., McMahon, K., \& McLaughlin, K. (2002). McLuhan's Wake. National Film Board, Canada. http://onf-nfb.gc.ca/en/our-collection/?idfilm=51036

Stake, R. E. (1995). The Art of Case Study Research. Thousand Oaks, CA: Sage Publications Inc.

Standage, T. (2017). The True History of Fake News. The Economist. https:/www.1843magazine.com/technology/rewind/the-true-history-of-fake-news

Templeton, J. (2019). I Ditched Google for DuckDuckGo: Here's Why You Should Too. Wired. https://www.wired.co.uk/article/duckduckgo-google-alternative-search-privacy

The Guardian (2020a). Cure Yourself of Fake News: How to Read about the Coronavirus. https://www.theguardian.com/world/2020/apr/11/the-cure-for-fake-news-how-to-read -about-the-coronavirus

The Guardian (2020b). Malicious Forces Creating Perfect Storm of Coronavirus Disinformation.

https://www.theguardian.com/world/2020/apr/24/coronavirus-sparks-perfect-storm-of -state-led-disinformation

Tolar-Burton, V., \& Chadwick, S. A. (2000). Investigating the Practices of Student Researchers: Patterns of Use and Criteria for Use of Internet and Library Sources. Computers and Composition, 17, 309-328. https://doi.org/10.1016/S8755-4615(00)00037-2

Voliva, C. O. (2016). We Can't Lose Our Libraries in Britain or North America. A Publication of the Public Libraries Association.

http://publiclibrariesonline.org/2016/04/we-cant-lose-our-public-libraries-in-britain-o r-america

Wang, V. C. X., \& Torrisi-Steele, G. (2015). Online Teaching, Change and Critical Theory. New Horizons in Adult Education and Human Resource Development, 27, 18-26. https://doi.org/10.1002/nha3.20108

Wikipedia (2020). Filter Bubble. https://en.wikipedia.org/wiki/Filter_bubble

Woolley, S. C., \& Howard, P. N. (2016). Political Communication, Computation Propaganda and Autonomous Agents. International Journal of Communication, 10, 48824890 .

Yin, K. E. (2017). Case Study Research: Design and Methods. Thousand Oaks, CA: Sage Publications. 